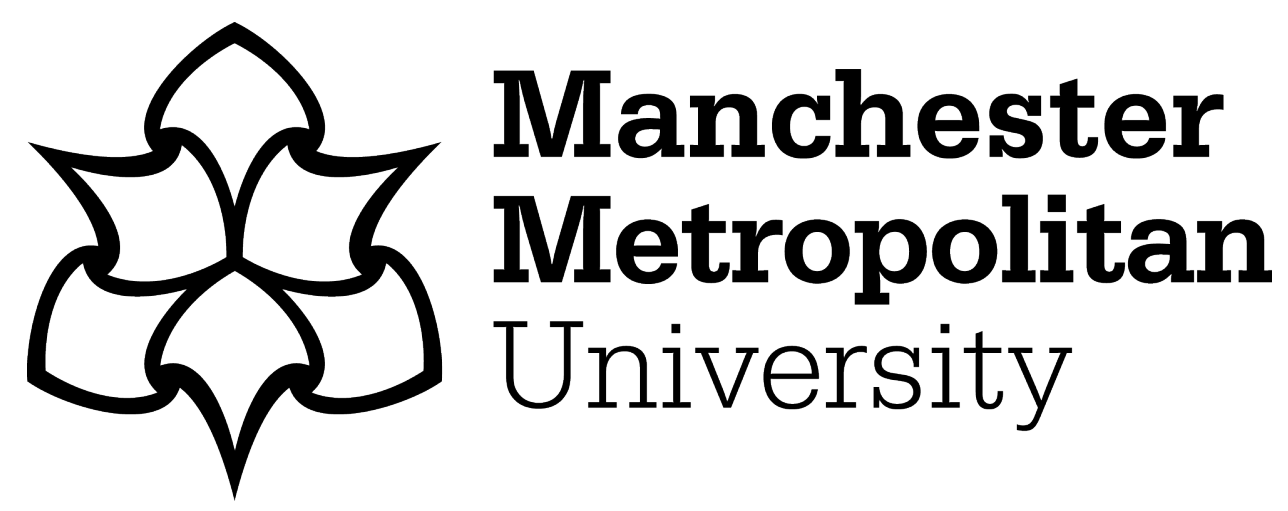

Southworth, Jamie S, Kohler, Sven and Pimblott, Simon M (2018) Gas Production from the Radiolysis of Water Adsorbed on $\mathrm{ZnO}$ Nanoparticles. Journal of Physical Chemistry C, 122 (44). pp. 25158-25164. ISSN 1932-7447

Downloaded from: https://e-space.mmu.ac.uk/621820/

Publisher: American Chemical Society

DOI: https://doi.org/10.1021/acs.jpcc.8b04276

Please cite the published version 


\title{
Gas Production from the Radiolysis of Water Adsorbed on ZnO Nano-Particles
}

\author{
Jamie S. Southworth a, b, Sven P. K. Koehler a, b, c, d and Simon M. Pimblott a, b, e *
}

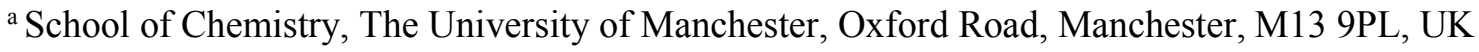 \\ ${ }^{\mathrm{b}}$ Dalton Cumbrian Facility, The University of Manchester, Westlakes Science \& Technology Park, \\ Moor Row, CA24 3HA, UK \\ c Photon Science Institute, The University of Manchester, Oxford Road, Manchester, M13 9PL, UK \\ ${ }^{\mathrm{d}}$ Current address: School of Science \& the Environment, Manchester Metropolitan University, \\ Chester Street, Manchester, M1 5GD, UK \\ ${ }^{\mathrm{e}}$ Current address: Idaho National Laboratory, Nuclear Science User Facilities, 995 University \\ Boulevard, Idaho Falls, ID 83401-0355, USA. \\ *Corresponding author: Jamie.southworth@postgrad.manchester.ac.uk
}

\begin{abstract}
The presence of a metal oxide surface can significantly alter the product yield distribution during the radiolysis of water. Some metal oxides such as $\mathrm{ZrO}_{2}$ or $\mathrm{CeO}_{2}$ have been shown to increase the yield of $\mathrm{H}_{2}$ during the irradiation of water adsorbed on the oxide as compared to liquid water, while other oxides such as $\mathrm{PuO}_{2}$ exhibit lower $\mathrm{H}_{2}$ yields. In this study, the $\gamma$-ray radiolysis of the $\mathrm{ZnO} / \mathrm{H}_{2} \mathrm{O}$ system was investigated. Surprisingly, both $\mathrm{O}_{2}$ and $\mathrm{H}_{2}$ were produced in similar quantities. The production of $\mathrm{O}_{2}$ is unexpected as no, or negligible, amounts of $\mathrm{O}_{2}$ have been observed for the radiolysis of water adsorbed on other oxides. Molecular oxygen production is observed during the radiolysis of both wet and dry $\mathrm{ZnO}$, indicating that the source of at least some of the $\mathrm{O}_{2}$ is the bulk oxide. The production of $\mathrm{H}_{2}$ due to the radiolysis of water adsorbed on $\mathrm{ZnO}$ is an order of magnitude greater than for pure water. This increase is likely due to an energy transfer process from the oxide to the adsorbed water molecules. However, the radiolysis of aqueous suspensions of $\mathrm{ZnO}$ resulted in lower radiolytic $\mathrm{H}_{2}$ yields than for pure water.
\end{abstract}




\section{Introduction}

The interaction of ionizing radiation with water adsorbed on the surface of metal oxides has been the subject of intense study in recent years, ${ }^{1,2,3,4,5,6}$ and the presence of certain metal oxides has been observed to have pronounced effects upon the yields of some important species produced during irradiation. ${ }^{7,8}$ While the radiation chemistry of pure water is well understood and the yields of radiolysis products are reliably established, the mechanisms underpinning radiolysis of water in the presence of a ceramic interface are not universally agreed. ${ }^{9,10}$

The radiolysis of water adsorbed on $\mathrm{ZrO}_{2}$ and $\mathrm{CeO}_{2}$ particles has been observed to increase the yield of $\mathrm{H}_{2}$ by up to four orders of magnitude compared to the yield for pure water. ${ }^{11}$ Conversely, it has been documented that certain metal oxides decrease the radiolytic yield of $\mathrm{H}_{2}$ relative to the radiolysis of pure water. ${ }^{8}$ An important example of an oxide which appears to decrease the yield of $\mathrm{H}_{2}$ is $\mathrm{PuO}_{2}$, a product of the reprocessing of spent nuclear fuel. ${ }^{12}$

Attempts to ascertain the oxidising products formed in the radiolytic splitting of water at an oxide surface have been inconclusive. For instance, when molecular oxygen $\left(\mathrm{O}_{2}\right)$ is detected from the radiolysis of water in the presence of metal oxides, it is in almost negligible volumes as $\mathrm{O}_{2}$ is a highly efficient scavenger of the $\mathrm{H}$ atom and the hydrated electron. ${ }^{13}$ This renders the detection of any quantities of $\mathrm{O}_{2}$ novel and worthy of further investigations. ${ }^{14}$

Phenomena such as the enhancement of the radiolytic yield of $\mathrm{H}_{2}$ or the radiolytic production of $\mathrm{O}_{2}$ in the presence of oxides common to the nuclear industry could give rise to operational and safety concerns. ${ }^{15,16}$ These include the pressurisation of waste containers, alteration of coolant water chemistry and hydriding of fuel cladding in reactor cores. For these reasons, the investigation of the radiation-induced chemistry, including the production of $\mathrm{H}_{2}$ and other species, of water in contact with metal oxides is of utmost importance, and understanding the mechanism of $\mathrm{H}_{2}$ production and common trends amongst various oxides are valuable. The exact mechanism behind the increased $\mathrm{H}_{2}$ yield during the radiolysis of water adsorbed on oxide surfaces is not known, but it must involve 
energy or charge transfer from the solid oxide to adsorbed water molecules leading to altered yields of molecular products, or changes of surface structure or morphology. ${ }^{17}$

The $\mathrm{Zn}$ cation is an important additive in the primary circuit coolant chemistry of light water reactors. It is added to reduce the build-up of radiation fields away from the reactor by replacing and limiting the incorporation of gamma emitting Co in oxide films. ${ }^{18}$ Petrik et al. have suggested that the presence of a zinc oxide, $\mathrm{ZnO}$, surface does not increase the radiolytic yield of $\mathrm{H}_{2} \cdot{ }^{8}$ It has also been reported that dry $\mathrm{ZnO}$ thermally releases $\mathrm{O}_{2}$ when heated to above ca. $400^{\circ} \mathrm{C} .{ }^{19}$ The oxide subsequently enters a sub-stoichiometric state, which is accompanied by a colour change from white to green/yellow. After cooling in an $\mathrm{O}_{2}$ rich atmosphere, the colour change is quickly reversed as the oxide re-absorbs $\mathrm{O}_{2}$. The sub-stoichiometry is documented as $\mathrm{Zn}_{(1+\mathrm{x})} \mathrm{O}$ where $\mathrm{x}=7.0 \times 10^{-4} \cdot{ }^{20}$ It has also been reported that the radiation tolerance of $\mathrm{ZnO}$ can be tuned by engineering specific defects into the lattice for increased stability in radiative environments. ${ }^{21}$

In this study, the effects of $\gamma$-irradiation on the water- $\mathrm{ZnO}$ system are investigated. First, the structure of the $\mathrm{ZnO}$ powder was determined by X-ray Diffraction (XRD) and the surface moieties were characterised by Diffuse Reflectance Infrared Fourier Transform (DRIFT) spectroscopy. The surface area and porosity of the oxide particles were determined by the Brunauer-Emmett-Teller (BET) method. Irradiations were performed using $1.173 \mathrm{MeV}$ and $1.332 \mathrm{MeV} \gamma$-rays from a 60 -Co source. The radiolysis of water adsorbed on the surface of $\mathrm{ZnO}$ particles and of water - $\mathrm{ZnO}$ slurries was examined by characterising and quantifying the gaseous products. The dependence of radiation dose upon the yield of $\mathrm{H}_{2}$ and $\mathrm{O}_{2}$ was also investigated, as was the variation of both products as a function of water loading on the oxide surface.

$\mathrm{H}_{2}$ and $\mathrm{O}_{2}$ were both detected, but not in stoichiometric quantities: Most interestingly, $\mathrm{O}_{2}$ was also detected from the irradiation of nominally dry $\mathrm{ZnO}$ particles, i.e. the interaction of ionising radiation with the $\mathrm{ZnO}$ powder seems to have a similar effect as compared to thermal treatment. 


\section{Experimental}

Zinc oxide (99.9\%) was purchased from Sigma Aldrich and used without further purification. The surface area and the estimated particle size were determined by the Brunauer-Emmett-Teller (BET) method using a Micromeritics TriStar II surface area analyser. Analysis of water and other contaminants on the surface of the powder was conducted using temperature dependent Diffuse Reflectance Infrared Fourier Transform (DRIFT) spectroscopy. DRIFT spectra were measured in situ with a Bruker Vortex 60 FT-IR spectrometer employing a Harrick Praying Mantis high temperature cell. X-Ray diffraction (XRD) measurements were taken using a Bruker D8 Powder X-ray Diffractometer. Scans were taken over $2 \theta$ values between $20^{\circ}$ and $85^{\circ}$ with a step size of $0.05^{\circ}$. Samples were kept static during measurements.

Prior to preparation by humidity control, samples were heated to $500^{\circ} \mathrm{C}$ for up to $36 \mathrm{~h}$ to remove adsorbed water and any residual organic contaminants from production. Heating to this temperature was not found to alter the specific surface area (determined by BET). The oxide was cooled and stored under vacuum, then weighed in sample tubes and finally placed in a constant humidity chamber. Sample tubes consist of $10 \mathrm{~mm}$ diameter Pyrex tubes $10 \mathrm{~cm}$ in length. The humidity of the chamber was controlled using saturated salt solutions and the percent relative humidity $(\% \mathrm{RH})$ measured using Testo $174 \mathrm{H}$ data loggers. ${ }^{22}$ After uptake of water, samples were re-weighed, followed by the sample tubes being purged with a positive pressure of argon ( $99.999 \%$ procured from BOC) and before being flame sealed. We also performed control experiments in which we irradiated empty, purged sample tubes, which did not generate a detectable amount of either $\mathrm{H}_{2}$ or $\mathrm{O}_{2}$.

Gamma-irradiation was performed using a Foss Therapy Services Inc. 812 self-contained 60-Co source. In July 2017, the dose rate was measured by Fricke dosimetry to be $442.7 \mathrm{~Gy} / \mathrm{min}$. Samples were irradiated with up to $36.5 \mathrm{kGy}$. The gases produced were measured (after cracking open the glass sample tubes under argon flow) using an SRI 8610C Gas Chromatograph (GC) equipped with a Thermal Conductivity Detector (TCD). Argon carrier gas was passed through a constant flow 
regulator, an injection loop connected to a four-way valve and into a column containing a molecular sieve.

The carrier gas selection determines the sensitivity of the TCD to the analyte gasses. In order for the TCD to have high sensitivity to a specific gas the thermal conductivity of the analyte must be significantly different to that of the carrier gas. ${ }^{23}$ There is a large difference in the thermal conductivities of $\mathrm{H}_{2}$ and $\mathrm{Ar}$, hence Ar was used as the carrier gas in the detection $\mathrm{H}_{2}$. In contrast, $\mathrm{Ar}$ has a similar thermal conductivity to $\mathrm{O}_{2}$, hence in this instance, He was selected as the carrier gas to increase $\mathrm{O}_{2}$ sensitivity. ${ }^{24}$

GC calibration was performed for each gas by injecting known quantities of either pre-mixed 5\% $\mathrm{H}_{2}$ in $\mathrm{Ar}$ or $5 \% \mathrm{O}_{2}$ in Ar calibration gases (Scientific and Technical Gases Ltd). Injections were performed using a Sample-Lok A2 gas tight microliter syringe (Sigma-Aldrich). The lower limit of detection of the GC is $1 \mu \mathrm{L}$, determined by injecting progressively smaller volumes until no signal was observed. $\mathrm{H}_{2}$ and $\mathrm{O}_{2}$ volumes were calculated from the $\mathrm{GC}$ output using the ideal gas law.

\section{Results and Discussion}

The diffraction pattern of $\mathrm{ZnO}$ powder used in this study was recorded both pre and post exposure to gamma irradiation. Comparison of the measured spectrum for the unirradiated powder with known XRD data ${ }^{25}$ suggests the crystal structure of the nano-particles is hexagonal (0001) wurtzite. $\gamma$ irradiation did not noticeably alter the crystal structure even at the maximum dose used in this study, $36.5 \mathrm{kGy}$. The figure is included in the supplementary information (Figure S1).

To compare the radiolytic $\mathrm{H}_{2}$ yields from water adsorbed on metal oxides for different measurements, and more importantly for a range of metal oxides, it is crucial to correctly quantify the amount of water adsorbed on the $\mathrm{ZnO}$ surface; here this parameter will be expressed as the average number of monolayers of water on the oxide surface. In order to calculate this quantity, the specific surface area (SSA) of the particles was determined by the BET method $\left(4.121 \pm 0.1 \mathrm{~m}^{2} / \mathrm{g}\right)$ and it is assumed that there are $10^{19}$ adsorption sites per $\mathrm{m}^{2}$. The shape of the isotherm (included in the supplementary data, 
Figure S2) indicates that the particles are non-porous. Making the assumption that the particles are spherical and non-porous, then based on the surface area, the average particle diameter is $\sim 270 \mathrm{~nm}$.

Figure 1 shows the increase in mass as a function of $\% \mathrm{RH}$ of the humidity chamber. Even when left for an extended period at $99.9 \%$ relative humidity, the maximum water coverage achieved is only 8 monolayers. In contrast, $\mathrm{ZrO}_{2}$ has been observed to adsorb three to four times that amount in the same time. ${ }^{11}$

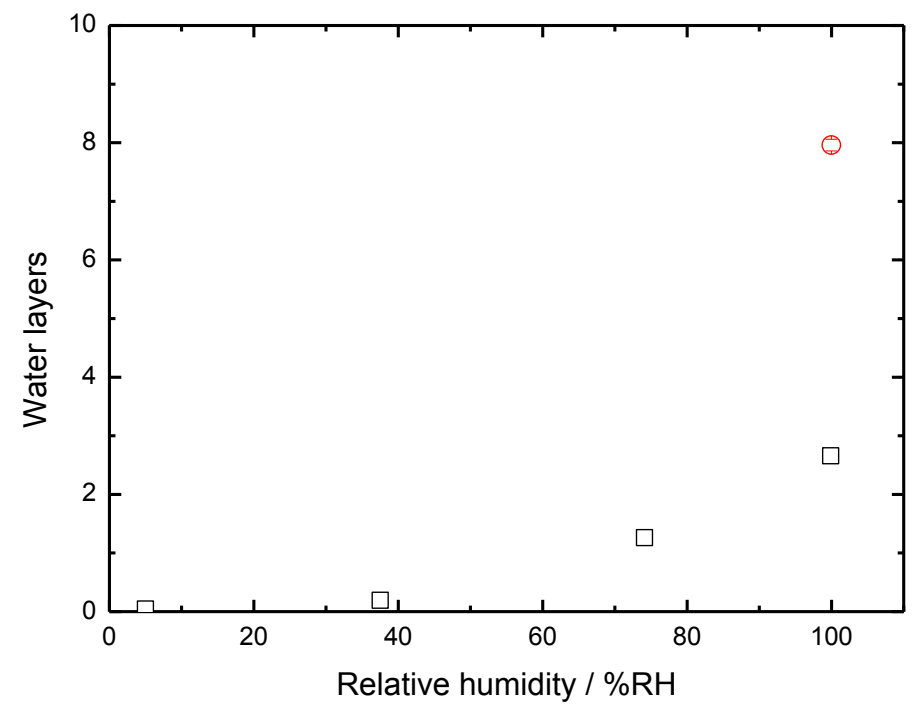

Figure 1 - Number of water layers adsorbed after 24 hours (口) by $\sim 1.0 \mathrm{~g}$ samples of $\mathrm{ZnO}$ as a function of relative humidity. After 14 days the coverage reaches a maximum of approximately 8 monolayers $(\circ)$. Error bars included however, they are hidden by the data points.

The number of monolayers is calculated from the difference in mass between the dry powder and the the powder post exposure to water vapour in the relative humidity chamber. The uptake of water on the surface of dry $\mathrm{ZnO}$ is a slow process with several days required to achieve more than two to three monolayers coverage.

DRIFT spectra of $\mathrm{ZnO}$ particles that had been left in a relative humidity chamber for 14 days at $99.9 \% \mathrm{RH}$ were recorded as a function of temperature to analyse the amount of intact water molecules 
present, shown in Figure 2. The spectra were recorded at $25^{\circ} \mathrm{C}, 100^{\circ} \mathrm{C}$, up to $500^{\circ} \mathrm{C}$ in incremental steps of $100^{\circ} \mathrm{C}$. The spectrum was then re-recorded once the sample had cooled to $25^{\circ} \mathrm{C}$.

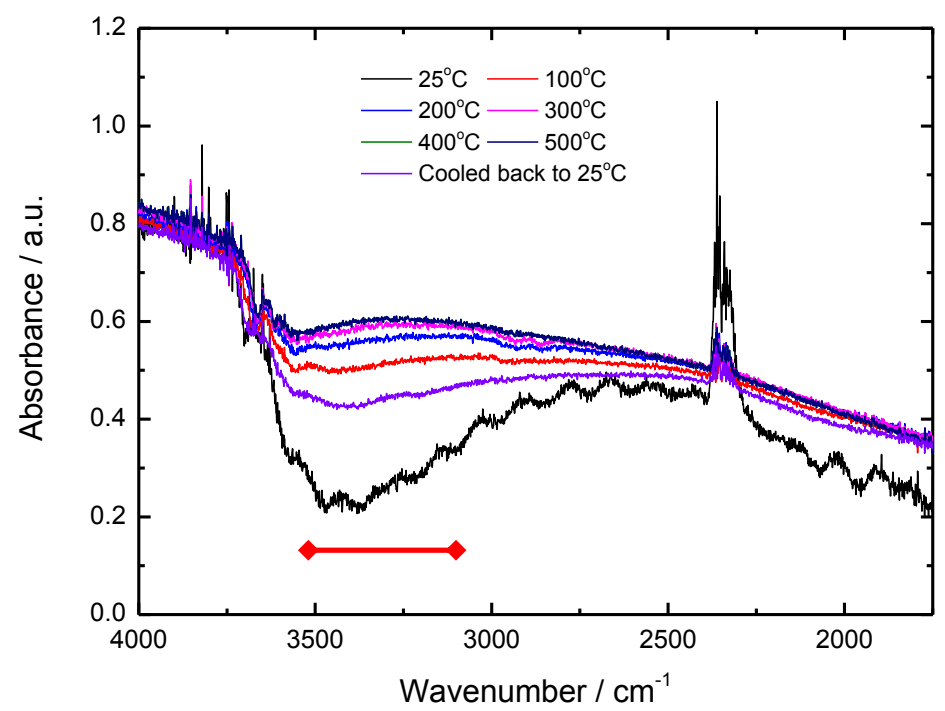

Figure 2 - DRIFT measurements taken at temperatures of $25^{\circ} \mathrm{C}, 100^{\circ} \mathrm{C}$, and in $100^{\circ} \mathrm{C}$ intervals until $500^{\circ} \mathrm{C}$. The spectrum was recorded again after the sample had cooled back to $25^{\circ} \mathrm{C}$. Free $\mathrm{OH}$ bond stretching vibrational frequency range is visible below $3500 \mathrm{~cm}^{-1}$, taken from Ref. [26] shown as the red bar under the spectrum.

The $\mathrm{OH}$ bond stretching vibrations between $3000 \mathrm{~cm}^{-1}$ and $3500 \mathrm{~cm}^{-1}$ (indicated by the red bar in Figure 2) are characteristic of undissociated water. ${ }^{26}$ The absorbance is strongest at $25^{\circ} \mathrm{C}$ and decreases in magnitude until at $500^{\circ} \mathrm{C}$ where it disappears. After allowing the sample to cool down to ambient temperature, the water absorbance does not re-appear. These data suggest heating the oxide sample to above $400^{\circ} \mathrm{C}$ will remove intact water molecules from the surface of the oxide down to surface coverages below the detection sensitivity of the spectrometer. We hence concluded that following heat treatment, coverages with undissociated water are expected to be well below one monolayer, although there may also be species from dissociatively chemisorbed water (such as $\mathrm{OH}$ groups) present on the surface. The feature at around $2250 \mathrm{~cm}^{-1}$ is due to the presence of gas phase $\mathrm{CO}_{2}$ in the headspace above the sample in the Harrick cell. 
In radiation chemistry, the yield of a species produced by ionizing radiation is usually expressed by the $\mathrm{G}$ value, which denotes the number of molecules of a species produced per $100 \mathrm{eV}$ of radiation energy deposited into the system. The $\mathrm{G}\left(\mathrm{H}_{2}\right)$ value for pure water with a small quantity of a hydroxyl radical scavenger (typically $0.1 \mathrm{mmol} \mathrm{KBr}$ ) to prevent recombination chemistry is well documented to be 0.45 molecules $/ 100 \mathrm{eV}$. This quantity translates to $\sim 0.45 \times 10^{-7} \mathrm{~mol} \mathrm{~J}^{-1}$ in SI units. ${ }^{27}$

When assessing radiation effects in multiphase systems (such as water/metal oxide systems), two options exist for quantifying the radiation dose received by a sample; the first approach is to calculate the dose received by the water-metal oxide system as a whole. The second approach is to only consider the dose received by the water adsorbed on the oxide. In this case, calculating the dose received with respect to adsorbed water only means any deviation from the yield for pure water can be attributed to processes caused by the presence of the oxide, such as the transfer of energy from the metal oxide to the water. ${ }^{10}$ In the following discussion, the dose of radiation received is calculated with respect to the mass of the adsorbed water only, as this allows identification of any effect due to the metal oxide. For instance, an increased yield might signify energy is transferred to the adsorbed water from the oxide while a decreased yield might suggest enhance recombination chemistry on the oxide surface.

The effect of the $\gamma$-radiation dose on the number of molecules of $\mathrm{H}_{2}$ produced by radiolysis of 1.2 monolayers of water adsorbed on $\mathrm{ZnO}$ nanoparticles is shown in Figure 3. The production of $\mathrm{H}_{2}$ increases linearly with radiation dose, over the dose range investigated. No $\mathrm{H}_{2}$ was observed for an unirradiated sample of wet $\mathrm{ZnO}$ powder, indicating that the production of $\mathrm{H}_{2}$ is a radiation effect, not a catalytic effect of the oxide alone. In addition, the irradiation of dry $\mathrm{ZnO}$ also yields no $\mathrm{H}_{2}$, indicating that the source of $\mathrm{H}_{2}$ is the adsorbed water. 


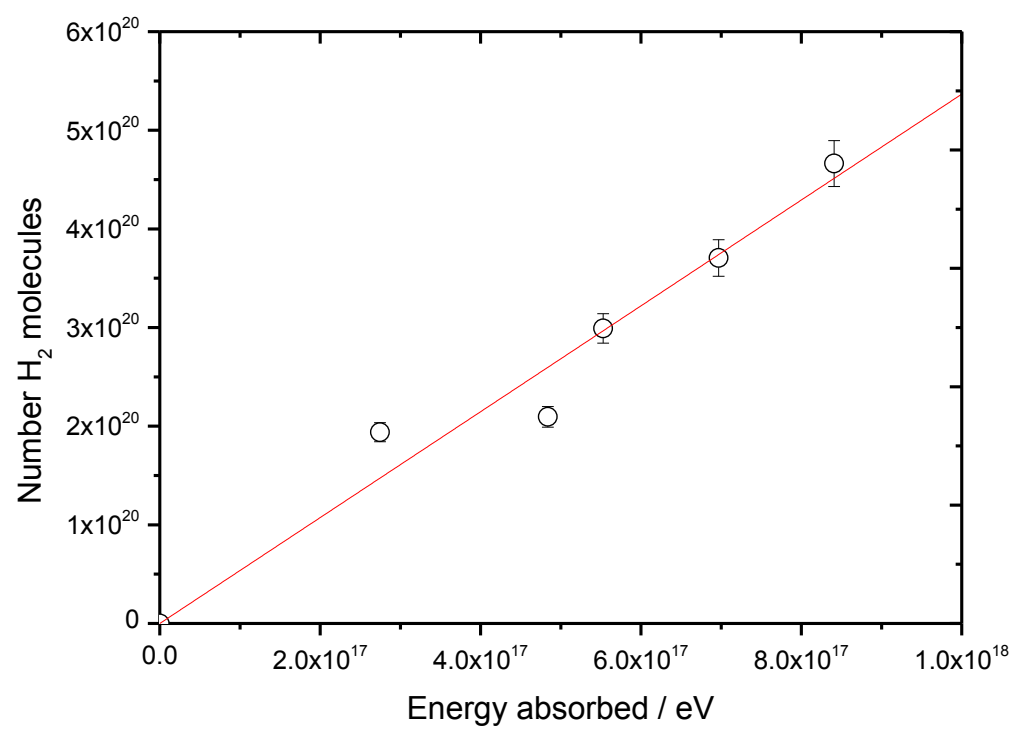

Figure 3 - Effect of dose absorbed by the water on $\mathrm{H}_{2}$ production from the $\gamma$-radiolysis of water adsorbed on $\mathrm{ZnO}$ particles with a surface area of $4.121 \mathrm{~m}^{2} / \mathrm{g}$. Water coverage is estimated to be 1.2 monolayers and $\mathrm{G}\left(\mathrm{H}_{2}\right)=5.56$ molecules $/ 100 \mathrm{eV}$ from the slope of the plot.

The yield of $\mathrm{H}_{2}$ produced, $\mathrm{G}\left(\mathrm{H}_{2}\right)$, is obtained from the slope of the best fit line to the experimental data in Figure 3. At 5.56 molecules/100 eV, the value from 1.2 monolayers of water adsorbed on $\mathrm{ZnO}$ is more than an order of magnitude greater than is observed for the radiolysis of pure water, 0.45 molecules $/ 100 \mathrm{eV}$. This result is in contrast to results by Petrik et al., who suggested that $\mathrm{ZnO}$ is part of the group of oxides which do not enhance the production of $\mathrm{H}_{2}$ from adsorbed water. The increase suggests that energy is transferred from the oxide to adsorbed water molecules. While the exact mechanism is not known, Petrik et al. have suggested that the enhanced production of $\mathrm{H}_{2}$ at water-oxide interfaces could be attributed to exciton (electrostatically bound electron-hole pair) formation in the bulk oxide due to the irradiation and subsequent exciton migration to the oxide/water interface. ${ }^{8}$ At the interface, exciton annihilation causes dissociation of the water molecules leading to the formation of $\mathrm{H}_{2} \cdot{ }^{28}$ Petrik et al. also postulate that the band gap of the oxide plays a role in determining the magnitude of enhancement in the $\mathrm{H}_{2}$ yield with the maximum enhancement being observed for oxides with a band gap of $\sim 5 \mathrm{eV}$ (such as $\left.\mathrm{ZrO}_{2}\right)^{29}$ which is close to the bond dissociation 
energy of the $\mathrm{H}-\mathrm{OH}$ bond of (adsorbed) water. ${ }^{8}$ Thus annihilation of a surface exciton at the wateroxide interface is postulated to lead to $\mathrm{H}-\mathrm{OH}$ bond breakage. In the case of $\mathrm{ZnO}$, the band gap is $3.3 \mathrm{eV}$, which is significantly less that $\mathrm{H}-\mathrm{OH}$ bond energy, yet the enhancement in the yield of $\mathrm{H}_{2}$ is considerable. ${ }^{30}$ LaVerne and co-workers have also observed significantly enhanced $\mathrm{H}_{2}$ production from water adsorbed on a variety of oxides including $\mathrm{CeO}_{2}, \mathrm{TiO}_{2}$ and $\mathrm{SiO}_{2}$ with band gaps different from $5 \mathrm{eV} \cdot{ }^{1,2,11,17,28}$

The amount of $\mathrm{O}_{2}$ produced from the radiolysis of 1.2 monolayers of water adsorbed to the surface of $\mathrm{ZnO}$ nanoparticles as a function of radiation dose to the water is shown in Figure 4. No $\mathrm{O}_{2}$ was detected from unirradiated $\mathrm{ZnO}$ samples, nor does water left in contact with $\mathrm{ZnO}$ without irradiation yield a detectable quantity of $\mathrm{O}_{2}$. The quantity of $\mathrm{O}_{2}$ produced radiolytically increases linearly with dose. The only previous observation of radiolytic production of $\mathrm{O}_{2}$ from water adsorbed on an oxide was made by LaVerne and Tandon, who detected $\mathrm{O}_{2}$ in amounts at least an order of magnitude lower than $\mathrm{H}_{2}$ production during their work on the radiolysis of water adsorbed on $\mathrm{UO}_{2} \cdot{ }^{31}$ This work on the radiolysis of water adsorbed on $\mathrm{ZnO}$ observes $\mathrm{O}_{2}$ production in similar yields to $\mathrm{H}_{2}$.

The yield of $\mathrm{O}_{2}, \mathrm{G}\left(\mathrm{O}_{2}\right)$, from the radiolysis of 1.2 monolayers of water adsorbed on $\mathrm{ZnO}$ determined from the gradient of the best fit to the data in Figure 4 is 2.067 molecules $/ 100 \mathrm{eV}$. The stable oxidising products typically detected during the radiolysis of water are $\mathrm{H}_{2} \mathrm{O}_{2}$ and $\mathrm{HO}_{2}$, while $\mathrm{O}_{2}$ is generally not observed. ${ }^{10} \mathrm{O}_{2}$ is efficient scavenger of hydrogen atoms and the hydrated electron and its precursors, and $\mathrm{O}_{2}$ molecules will readily react with these species to form either the hydroperoxyl radical or the superoxide radical anion. These secondary radical species will then further react to form $\mathrm{H}_{2} \mathrm{O}_{2}$ and re-form $\mathrm{O}_{2}$. 


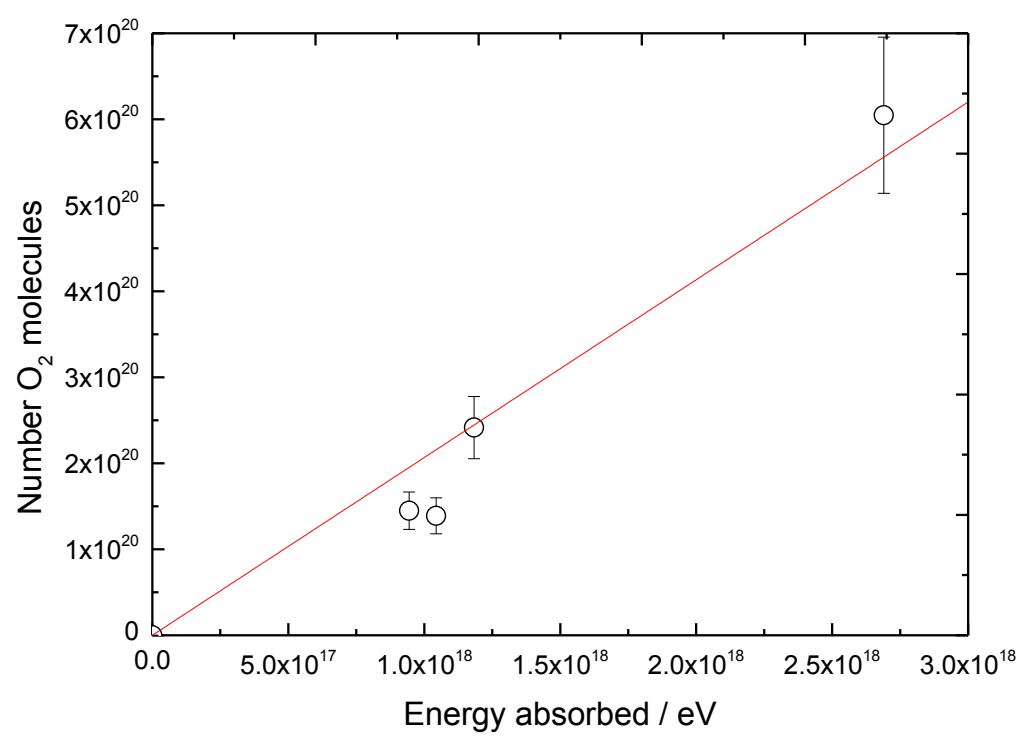

Figure 4- Dose dependence of $\mathrm{O}_{2}$ produced from the radiolysis of 1.2 monolayers of water adsorbed to the surface of $\mathrm{ZnO}$ nanoparticles. Dose calculated for energy absorbed by the adsorbed water only. Here, $\mathrm{G}\left(\mathrm{O}_{2}\right)=2.067$ molecules $/ 100 \mathrm{eV}$.

While the amounts of $\mathrm{O}_{2}$ and $\mathrm{H}_{2}$ detected from the radiolysis of 1.2 monolayers of water adsorbed on $\mathrm{ZnO}$ nanoparticles are similar, they are not stoichiometric. The yield of $\mathrm{O}_{2}$ is about four times that of $\mathrm{H}_{2}$ rather than the "expected" 2:1 ratio. This difference indicates that the source of $\mathrm{O}_{2}$ may not the adsorbed water, but the $\mathrm{ZnO}$ itself. Furthermore, $\mathrm{O}_{2}$ is not produced unless the oxide is irradiated suggesting that the production of $\mathrm{O}_{2}$ is not a catalytic effect of the oxide alone, but due to the interaction of radiation with the oxide. When the dose is calculated with respect to the energy absorbed by the mass of the oxide and water, $\mathrm{G}\left(\mathrm{O}_{2}\right)=2.067$ molecules $/ 100 \mathrm{eV}$.

Figure 5 shows the volume of $\mathrm{O}_{2}$ produced from irradiation of $\sim 1.0 \mathrm{~g}$ of dry $\mathrm{ZnO}$ as a function of dose to the oxide. Even dry samples of $\mathrm{ZnO}$, which were not exposed to water vapor in a relative humidity chamber, generated $\mathrm{O}_{2}$ when irradiated, with the rate of production increasing linearly with dose. The yield of $\mathrm{O}_{2}$ determined from Figure 5 is $\mathrm{G}\left(\mathrm{O}_{2}\right)=8.34 \times 10^{-3}$ molecules $/ 100 \mathrm{eV}$ (with the absorbed energy calculated with respect to the mass of the oxide). 


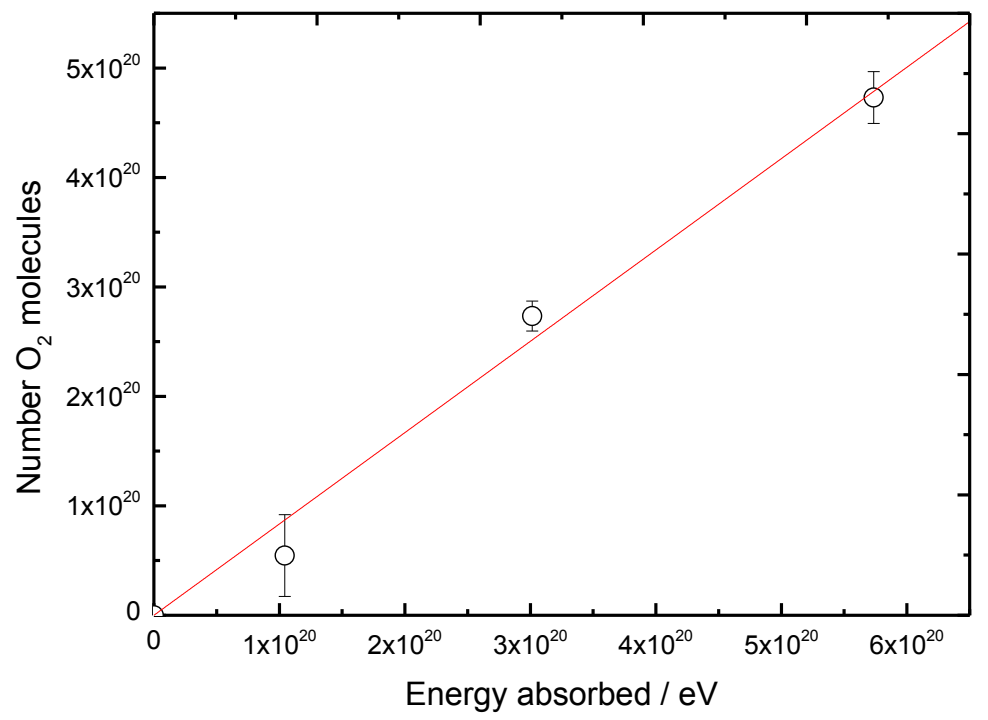

Figure 5 - Number of molecules of $\mathrm{O}_{2}$ produced as a function energy absorbed from the radiolysis of $1.0 \mathrm{~g}$ dry $\mathrm{ZnO}$ nano-powder. $\mathrm{G}\left(\mathrm{O}_{2}\right)=8.34 \times 10^{-3}$ molecules $/ 100 \mathrm{eV}$ for dry $\mathrm{ZnO}$, with the dose calculated with respect to the mass of the oxide.

Observing $\mathrm{O}_{2}$, but not $\mathrm{H}_{2}$, during the irradiation of the dry oxide samples clearly demonstrates that the source of $\mathrm{O}_{2}$ is the oxide, and it is not produced due to the decomposition of physisorbed water molecules. However, it is not possible to rule out dissociatively chemisorbed water/OH groups as the potential source of $\mathrm{O}_{2}$.

As briefly mentioned previously, it is known that thermal treatment of $\mathrm{ZnO}$ can lead to a reduction of the oxide; the sub-stoichiometry that arises from the thermal treatment of $\mathrm{ZnO}$ to above $400^{\circ} \mathrm{C}$ is reported to be $\mathrm{Zn}_{(1+\mathrm{x})} \mathrm{O}$ where $\mathrm{x}=7.0 \times 10^{-4} \cdot{ }^{20,20}$ Based on this stoichiometry, heating $1.0 \mathrm{~g}$ of $\mathrm{ZnO}$ should produce about $87 \mu \mathrm{L}$ of $\mathrm{O}_{2}$. This value is of the same magnitude as the volumes measured in this work, which strongly suggests that $\gamma$-irradiation reduces $\mathrm{ZnO}$ in a similar vein as thermal treatment of $\mathrm{ZnO}$. This colour change is also observed during gamma irradiation, which is quickly reversed upon exposure to an $\mathrm{O}_{2}$ rich atmosphere. 
While the previous discussion was centred around $\mathrm{H}_{2}$ production from 1.2 adsorbed monolayers of water on $\mathrm{ZnO}$ nanoparticles, we have repeated these experiments for further coverages to extract $\mathrm{G}\left(\mathrm{H}_{2}\right)$ values as a function of the average number of water layers, see Figure 6.

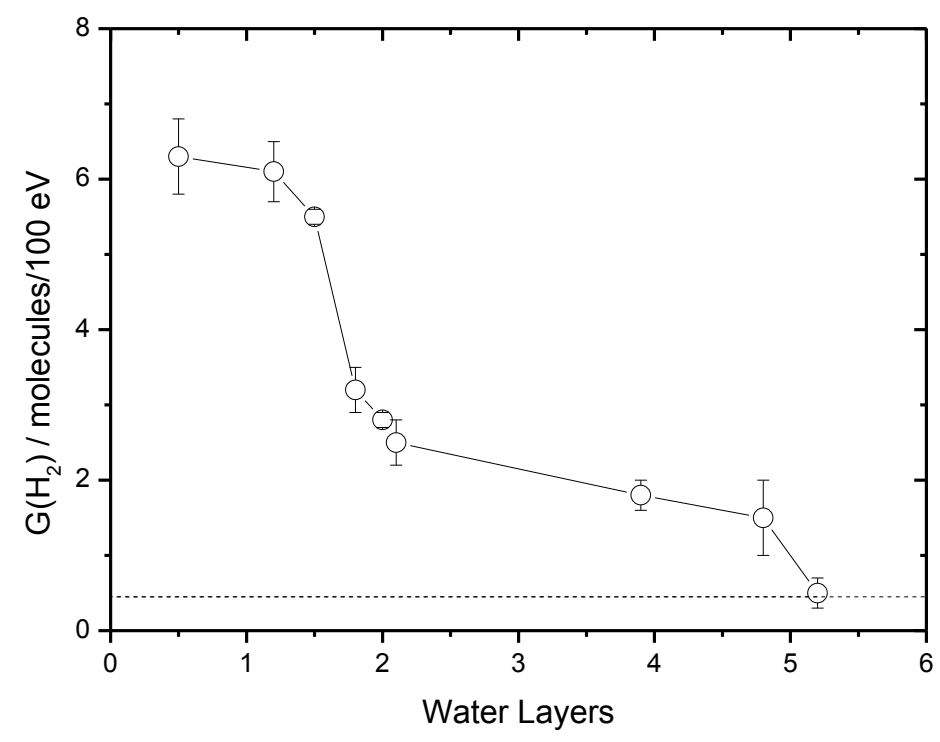

Figure 6 - Yield of $\mathrm{H}_{2}$ as a function of the number of water layers adsorbed on $\mathrm{ZnO}$. The $\mathrm{G}\left(\mathrm{H}_{2}\right)$ value for the radiolysis of pure water is 0.45 molecules $/ 100 \mathrm{eV}$, shown as a dashed line for comparison. A colour change of white to yellow/green was also observed during $\gamma$-irradiation.

In order to explain these experimental results, it is worth comparing the observed G-values for $\mathrm{H}_{2}$ production with those for other metal oxides. Experiments investigating the radiolysis of water adsorbed on $\mathrm{ZrO}_{2}$ and $\mathrm{CeO}_{2}$ particles found $\mathrm{G}\left(\mathrm{H}_{2}\right)$ values of 150 molecules/100 eV and 20 molecules/100 eV, respectively. ${ }^{11}$ The radiation-catalytic activity of $\mathrm{ZnO}$ towards $\mathrm{H}_{2}$ production is much less than for $\mathrm{ZrO}_{2}$. This discrepancy may be explained in part by the (larger) difference between the band gap for $\mathrm{ZnO}$ and the $\mathrm{H}-\mathrm{OH}$ bond strengths as compared to $\mathrm{ZrO}_{2}$. However, some form of energy transfer must still take place, as otherwise $\mathrm{G}\left(\mathrm{H}_{2}\right)$ values similar to deaerated water (0.45 molecules $/ 100 \mathrm{eV})$ would be expected.

The $\mathrm{G}\left(\mathrm{H}_{2}\right)$ values in the experiments $\mathrm{ZrO}_{2}$ and $\mathrm{CeO}_{2}$ show a sharp rise in $\mathrm{G}\left(\mathrm{H}_{2}\right)$ as the water loading is decreased, ${ }^{11}$ which is not observed for $\mathrm{ZnO}$. The yields for all oxides, however, should decrease to 
the value for deaerated water as the water loading on the oxide increases; this is because the influence of the substrate is felt less and less as the water coverages increases, and outer water layers are further removed from the oxide interface. Since it is reasonable to assume that the propagation of excitons through the adsorbed water layers is independent of the metal substrate, it seems that the lower $\mathrm{G}\left(\mathrm{H}_{2}\right)$ values for $\mathrm{ZnO}$ are due to a less efficient energy transfer from the oxide to the adsorbed water.

$\mathrm{H}_{2}$ production from the radiolysis of aqueous suspensions of $\mathrm{ZnO}$ in water has also been investigated. The amount of $\mathrm{ZnO}$ present (in terms of weight percent) was varied from $1 \%$ to $90 \%$, shown in Figures 7(a) and (b).

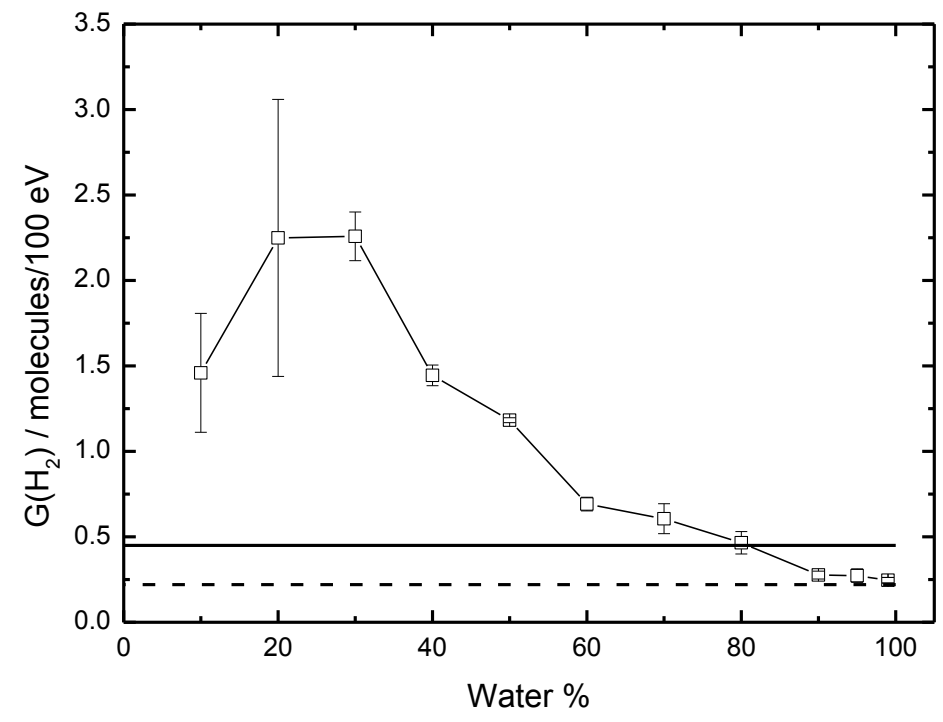

Figure 7a- Yield of $\mathrm{H}_{2}$ as a function of the weight percentage of water when $\mathrm{G}\left(\mathrm{H}_{2}\right)$ calculated with respect to dose absorbed by $\mathrm{H}_{2} \mathrm{O}$ only. Solid horizontal line indicates the value for $0.1 \mathrm{mmol} \mathrm{KBr}$ $(\sim 0.45$ molecules $/ 100 \mathrm{eV})$, dashed line indicates pure water $(\sim 0.22$ molecules $/ 100 \mathrm{eV})$. 


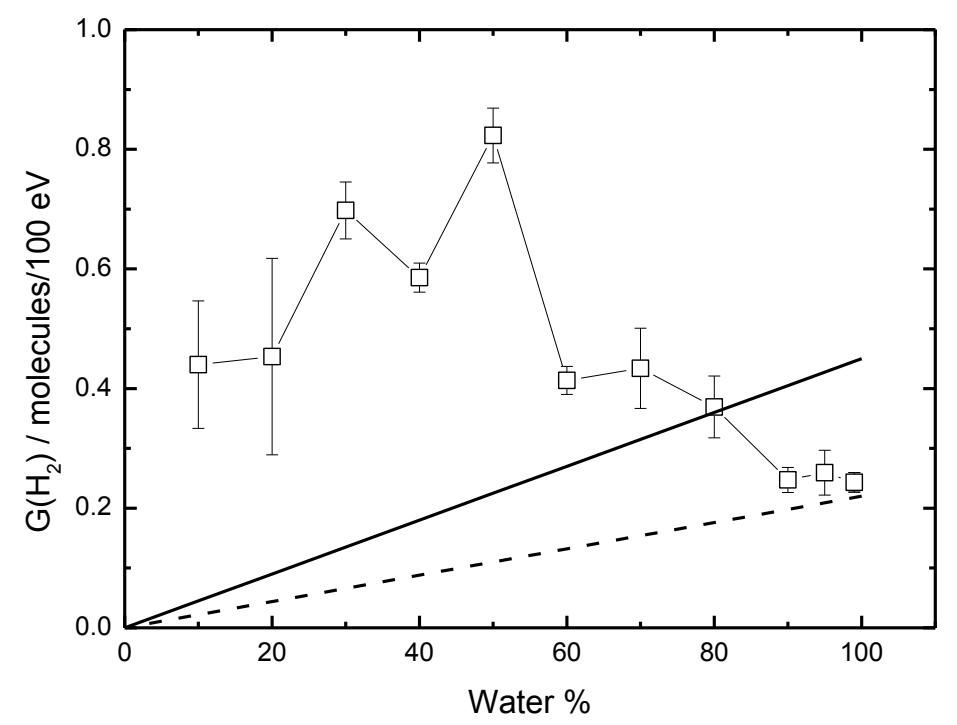

Figure 7b- Yield of $\mathrm{H}_{2}$ as a function of the weight percentage of water when $\mathrm{G}\left(\mathrm{H}_{2}\right)$ calculated with respect to dose absorbed by $\mathrm{ZnO}$ and $\mathrm{H}_{2} \mathrm{O}$. Solid line indicates the value for $0.1 \mathrm{mmol} \mathrm{KBr}(\sim 0.45 \mathrm{molecules} / 100 \mathrm{eV})$, dashed line indicates pure water $(\sim 0.22$ molecules $/ 100 \mathrm{eV})$.

Figure 7(a) and (b) shows the variation in $\mathrm{G}\left(\mathrm{H}_{2}\right)$ with weight percent water with the G-value calculated relative to the amount of energy deposited in the water only in Figure $7 \mathrm{a}$ and relative to the amount of energy deposited in the water and the oxide (Figure $7 \mathrm{~b}$ ). The figures also include lines showing the expected G-value for $\mathrm{H}_{2}$ that would be expected if it was produced solely from the radiolysis of water (deaerated or with $0.1 \mathrm{mmol} \mathrm{KBr}$ ). The energy deposited to the two phases is calculated according to the "mixture law" which states that the fraction of the total energy initially deposited into a multicomponent mixture is proportional to the electron density (or the mean mass collision stopping power) of each component. ${ }^{32}$

At $20 \%$ water, the samples can be more accurately described as a damp powder or a paste than an aqueous suspension/slurry. Water is not evenly distributed about the oxide powder, which is thought to give rise to the error associated with this measurement.

These data show that as the weight $\%$ of water increases, $\mathrm{G}\left(\mathrm{H}_{2}\right)$ decreases. One would expect this as the influence of energy transfer processes occurring from the oxide to the water phase becomes less 
pronounced as the amount of water approaches $100 \%$. Interestingly, as the percentage water present reaches $100 \%, \mathrm{G}\left(\mathrm{H}_{2}\right)$ tends towards the value observed for the radiolysis of pure water alone (measured as 0.22 molecules $/ 100 \mathrm{eV}$ - dashed lines in Figure $7 \mathrm{a}$ and $7 \mathrm{~b}$ ). This is at odds with work done on other water/oxide systems - namely aqueous suspensions of $\mathrm{ZrO}_{2}$ and $\mathrm{Al}_{2} \mathrm{O}_{3}{ }^{28,33} \mathrm{G}\left(\mathrm{H}_{2}\right)$ for zirconia and alumina slurries falls to approximately the value for deaerated water with a radical scavenger $(0.45$ molecules $/ 100 \mathrm{eV})$, indicating that oxide particles scavenge $\mathrm{OH}$ radicals. In this case, it appears that $\mathrm{ZnO}$ is unreactive towards radiation-produced radicals and therefore, it does not break the reaction chain and is inert. 


\section{Conclusion}

The $\gamma$-radiolysis of dry $\mathrm{ZnO}$ and water adsorbed on $\mathrm{ZnO}$ powder was examined. Following irradiation, no change in the bulk crystal structure was detected by XRD up to a dose of $36.5 \mathrm{kGy}$, nor was there any change in surface area as measured by the BET method.

Most strikingly, the production of $\mathrm{O}_{2}$ was observed in comparable amounts to $\mathrm{H}_{2}$ during the radiolysis of water adsorbed to $\mathrm{ZnO}$. The volume of $\mathrm{O}_{2}$ was observed to increase linearly with dose, and $\mathrm{O}_{2}$ was even observed after irradiation of dry $\mathrm{ZnO}$ powder. $\mathrm{O}_{2}$ has never previously been observed in similar quantities to $\mathrm{H}_{2}$ during irradiation experiments with any other metal oxides. In analogy with the wellknown thermal reduction of $\mathrm{ZnO}$, we conclude that the $\mathrm{ZnO}$ itself appears to be the most likely source of oxygen in these experiments.

Molecular hydrogen yields from the radiolysis of water adsorbed to $\mathrm{ZnO}$ nano-particles were an order of magnitude greater than $\mathrm{G}\left(\mathrm{H}_{2}\right)$ from pure water. $\mathrm{G}\left(\mathrm{H}_{2}\right)$ was observed to decrease as the number of water layers increased, which indicates that some form of energy transfer from the $\mathrm{ZnO}$ particle to the adsorbed water layers takes place. The increased $\mathrm{H}_{2}$ yields, however, are less pronounced compared to other oxides previously studied, suggesting a less-efficient energy transfer mechanism.

The amount of $\mathrm{H}_{2}$ detected from the radiolysis of aqueous suspensions of $\mathrm{ZnO}$ was lower than the value observed for radically scavenged water, but in line with the value observed for pure water. This indicates that $\mathrm{ZnO}$ is inert to radiation-produced radicals in aqueous solution.

\section{Acknowledgments}

This work was jointly funded by EPSRC and Nuclear Decommissioning Authority. The research described was carried out at the Dalton Cumbrian Facility, The University of Manchester and the authors thank all the staff and students kindly for their time and assistance. 


\section{References}

${ }^{1}$ Rieff. S. C, LaVerne. J. A, J. Phys. Chem. B, 2015, 119, 7358-7365

${ }^{2}$ Rieff. S. C, LaVerne. J. A, J. Phys. Chem. C, 2015, 119, 8821-8828

${ }^{3}$ Roth. O, Dahlgren. B, LaVerne. J. A, J. Phys. Chem. C, 2012, 116, 17619-17624

${ }^{4}$ Sunder. S, Boyer. G. D, Miller. N. H, J Nuc. Mat., 1990, 175, 163-169

${ }^{5}$ Skotnicki. K, Bobrowski. K, J. Rad. Nuc. Chem., 2015, 304, 473-480

${ }^{6}$ Carrasco- Flores. E. A, LaVerne. J. A, J. Chem. Phys., 2007, 127, 234703

${ }^{7}$ Le Caër. S, Water, 2011, 3, 235-253

${ }^{8}$ Petrik. N. G, Alexandrov. A. B, Vall. A. I; J. Phys. Chem. B, 2001, 105, 5935-5944

${ }^{9}$ Burton. M, J. Phys. Chem., 1947, 51, 611-625

${ }^{10}$ Spinks. J. W. T, Woods. R. J, An Introduction to Radiation Chemistry, $3^{\text {rd }}$ Edition, John Wiley \& Sons, Inc, New York, 1964, 39-77

${ }^{11}$ LaVerne. J. A, Tandon. L, J. Phys. Chem. B, 2002, 106, 380-386

${ }^{12}$ Sims. H. E, Webb. K. J, Brown. J, Morris. J, Taylor. J. R, J. Nuc. Mater., 2013, 437, 359-364

${ }^{13}$ Barr. N. F, Allen. A. O, J. Phys. Chem., 1959, 63, 928-931

${ }^{14}$ LaVerne. J. A, Radiat. Res., 2000, 153, 487

${ }^{15}$ Hiroki. A, LaVerne J. A, J. Phys. Chem. B, 2005, 109, 3364-3370

${ }^{16}$ Sterniczuk. M, Bartels. D. M, J. Phys. Chem. A, 2016, 120, 200-209

${ }^{17}$ Schofield. J, Reiff. S. C, Pimblott. S. M, LaVerne. J. A, J. Nuc. Mater., 2016, 469, 43-50

${ }^{18}$ Puyane. R, J. Mater. Processing Technology, 1996, 56, 863-872

${ }^{19}$ Coogan. C. K, Rees. A. L. G, J. Chem. Phys., 1942, 20, 1650-1651

${ }^{20}$ Wieberg. E, Holleman. A. F, Lehrbuch der Anorganischen Chemie, de Gruyter, Berlin, 101, 1995

${ }^{21}$ Lv. J, Li. X, Phys. Chem. Chem. Phys., 2018, 20, 11882-11887

${ }^{22}$ Young. J. F, J. Appl. Chem., 1967, 17, 241-245

23 Johnston. H. L, Grilly. E. R, J. Chem. Phys., 1946, 14, 233-238

${ }^{24}$ Guildner. L. A, Journal of Research of the National Bureau of Standards, 1975, 79A, 407-413

${ }^{25}$ Pacholski. C, Kornowski. A, Weller. H, Angew. Chem. Int. Ed, 2002, 41, 1189-1191

${ }^{26}$ Hudgins. D, Sandford. S, Allamandola. L, Tielems. A, Astrophys. J. Suppl. Ser, 1993, 86, 713-870

${ }^{27}$ Rotureau. P, Renault. J. P, Lebeau. B, Patarin. J, Mialocq. J. C, ChemPhysChem, 2005,6, 1316-1323

${ }^{28}$ LaVerne. J. A, Tonnies. S. E, J. Phys. Chem. B, 2003, 107, 7277-7820

${ }^{29}$ Aleksandrov. A. B, Bychkov. A. Y, Vall. A. I, Petrik. N. G, Sedov. V. M, Russian J. Phys. Chem., 1991, 65, 1604-1608

${ }^{30}$ Debanath, M. K, Karmakar. S, Materials Letters, 2013, 111, 116-119

${ }^{31}$ LaVerne. J. A, Tandon. L, J. Phys. Chem. B, 2003, 107, 13623-13628

${ }^{32}$ Baidak. A, LaVerne. J. A, J. Nuc. Mat., 2010, 407, 211-219

${ }^{33}$ Rieff. S. C, LaVerne. J. A, Rad. Phys. and Chem., 2017, 131, 46-50 


\section{Supplementary Information}

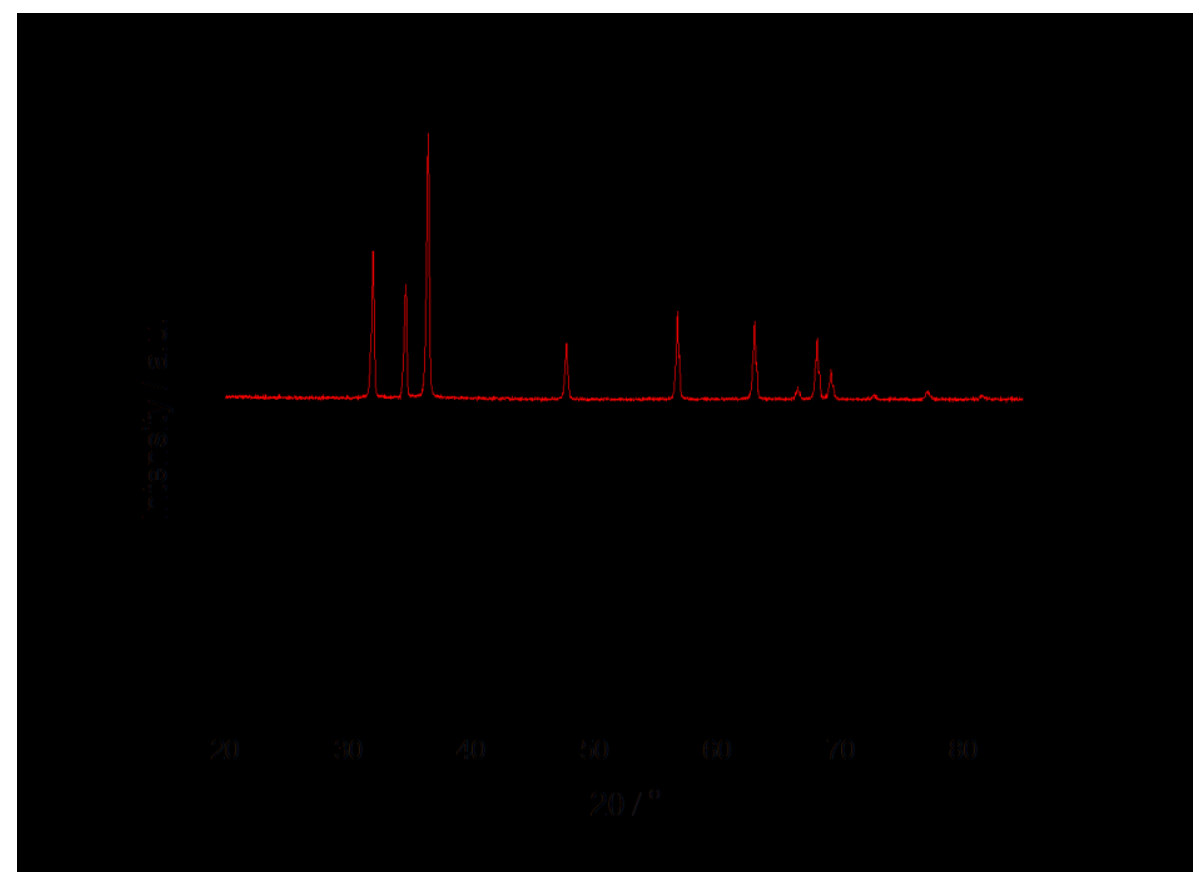

Figure S1- X-ray diffraction patterns of $\mathrm{ZnO}$ before irradiation (top, red) and after $\gamma$-irradiation to a dose of $36.5 \mathrm{kGy}$ (bottom, black) which was not observed to change the crystal structure. Assignment in agreement with Ref. [25]. 


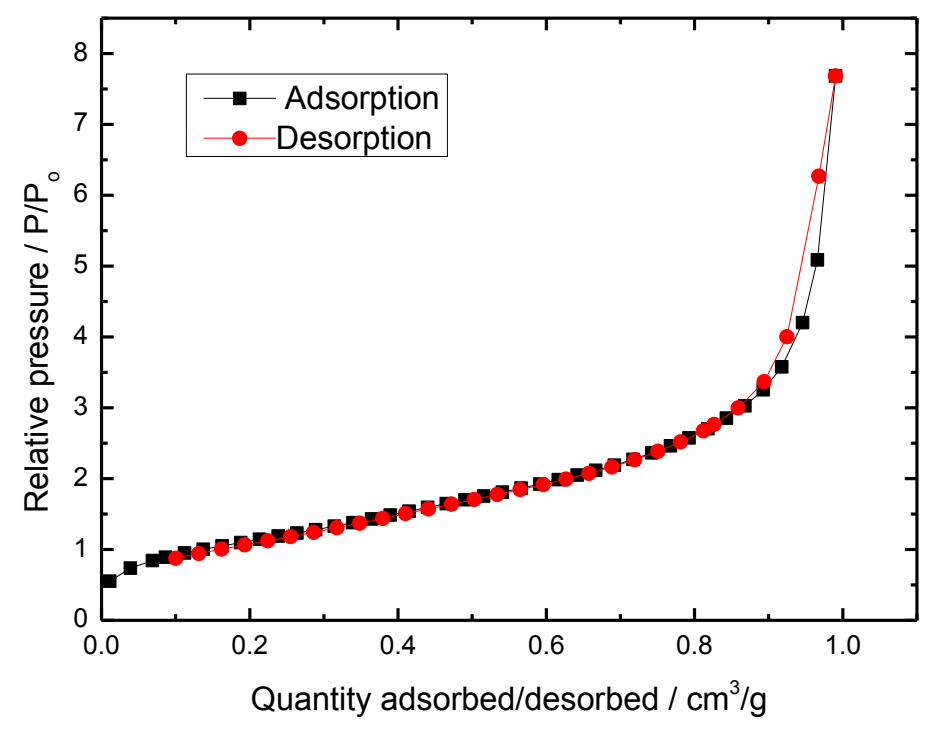

Figure S2- Full adsorption/desorption isotherm (using $\mathrm{N}_{2}$ ) used to determine the BET surface area of $\mathrm{ZnO}$ nano-particles which was, in this case, $4.121 \pm 0.1 \mathrm{~m}^{2} / \mathrm{g}$. The shape of the isotherm and lack of hysteresis loop indicates that the particles are highly non-porous. 